\title{
The Relationship Between Perceived Coaching Behaviours, Motivation and Self-Efficacy in Wrestlers
}

\author{
by \\ Ihsan Sart ${ }^{1}$, Betül Bayazıt ${ }^{2}$
}

\begin{abstract}
The current study aimed to determine the relationship between perceived coaching behaviours, motivation, selfefficacy and general self-efficacy of wrestlers who competed in the Super National Wrestling League. The sample consisted of 289 wrestlers. The Self-Efficacy Scale was used to measure self-efficacy perception, the Sports Motivation Scale to measure the motivation of the athletes, the Leadership Scale for Sport to determine perceived leadership behaviours, and the General Self-Efficacy Scale to determine the general self-efficacy perceptions of the athletes. For data analyses, SPSS 17.0 software was used. According to the results of the regression analyses performed with the enter method, it was found that perceived training and instruction behaviour along with perceived social support behaviour significantly explained self-efficacy (adjusted $R^{2}=.03$ ), intrinsic motivation (adjusted $R^{2}=.04$ ) and amotivation (adjusted $\left.R^{2}-=.05\right)$. Also, perceived training and instruction behaviour $(\beta=.51)$, autocratic behaviour $(\beta=-.17)$ and social support behaviour ( $\beta=-.27$ ) significantly contributed to athletes' general self-efficacy (adjusted $R^{2}=.10$ ). In light of these findings, it may be argued that perceived training and instruction behaviour may be beneficial for selfefficacy, general self-efficacy, intrinsic motivation, and amotivation. On the other hand, it could be stated that perceived autocratic behaviour may be detrimental for general self-efficacy of the athletes. As for social support behaviour, it may be suggested that it is negatively related to self-efficacy, general self-efficacy and intrinsic motivation. Lastly, a positive relationship was observed between perceived social support behaviour and amotivation in wrestlers. The results reveal the specific characteristics of wrestlers and suggest some implications for wrestling coaches.
\end{abstract}

Key words: leadership, self-efficacy, motivation, coaching behaviours, wrestling.

\section{Introduction}

Social and psychological factors that affect athletes' behaviour have recently been examined in detail and it has been emphasised that coaches are one of the most important social agents in this regard (Jõesaar et al., 2012). No matter how capable and hard-working the athletes in a team are, it is impossible for them to achieve success unless they are properly guided and improved, both technically and tactically. The coach is a sports person who guides the athletes in line with their skills, trains and prepares them for competition, and leads them by combining theoretical knowledge with experience (Doğan, 2004). Every behaviour of coaches is important for their athletes. Furthermore, even coaches' expectations for athletes could affect athletes' performance which is also known as the Pygmalion effect (Weaver et al., 2016).

One of the most frequently used theoretical models of leadership in sport is "the Multidimensional Leadership Model" which was proposed by Chelladurai (1990; 1993). According to Chelladurai (1993), there are five dimensions of leadership behaviour in coaching i.e., training/instruction, democratic, autocratic, social support and positive feedback behaviours. Training/instruction behaviour prioritizes training and instructing the athletes to achieve their

1 - Sakarya University, Faculty of Sport Sciences.

2 - Kocaeli University, Faculty of Sport Sciences. 
performance aims; democratic behaviour involves sharing opinions with the athletes; autocratic behaviour means that athletes cannot always participate in the decision-making process; social support behaviour focuses on forming mutual relationships with the athletes; lastly, positive feedback involves complimenting athletes and encouraging them to achieve success in performance (Bum and Shin, 2015). These five dimensions were examined by numerous researchers (Bum and Shin, 2015; Eskiyecek et al., 2015; Hollembeak and Amorose, 2005; Reinboth et al., 2004; Wu et al., 2014). However, there are also some studies in which coaching behaviours were examined from a different perspective. Some of these studies focused on supportive and unsupportive coaching behaviour (Nicolas et al., 2011; Nicholls et al., 2016), autonomy supportive coaching behaviour (Adie et al., 2008; Cheval et al., 2017; Stebbings et al., 2011) and controlling coaching behaviour (Barcza-Renner et al., 2016; Cheval et al., 2017; Stebbings et al., 2011).

As a result of the advances in sport coaching and sciences, the importance of leadership in sports has increased and it has been concluded that leadership is one of the most important tasks of a coach (Körük et al., 2003). The leadership behaviours of coaches become important in the sense that they affect the athletes in many aspects during their long time relationships, in which athletes develop interactions with coaches. In the literature, the correlation of leadership behaviours with many other variables has been investigated with attempts to determine the effective leadership behaviours. Considering the available literature, it may be observed that correlations between coaching behaviours and goal orientation (Toros, 2011), team cohesion (Toros, 2011), self-efficacy (Cengiz et al., 2012), intrinsic motivation (Matosic et al., 2014), competitive anxiety (Ledochowski et al., 2012), collective efficacy (Toros and Duvan, 2011), basic psychological needs (Reinboth et al., 2004) and burnout (Vealey et al., 1998) have been of great interest of researchers.

As explained above, parallel to the effects the sports coaches have on athletes, it may be stated that coaching behaviours may affect athletes' motivation. Motivation is defined as "the investigation of the energisation and direction of behaviour" (Roberts and Treasure, 2001), thus, it comprises the reasons for a certain behaviour (Clancy et al., 2016). Motivation is one of the most important factors that may affect sporting achievements (Körük et al., 2003). Therefore, studies conducted on the factors that may affect athletes' motivation levels can help obtain better results and provide positive experiences for athletes.

The Self Determination Theory (Deci and Ryan, 1985) proposes a continuum in which the two types of motivation i.e., intrinsic and extrinsic exist at opposite ends, though theorists acknowledge that both sources of motivation may simultaneously occur. In intrinsic motivation, behaviour itself becomes the pleasure, for example, participating in an activity for fun (Kaufmann et al., 2011), and people join these activities as they are interested in them and take pleasure from them (Altıntaş et al., 2013). In extrinsic motivation, behaviours are performed in order to attain a certain result (Morsünbül, 2012). People playing sports in order to have a career may be considered as an example of extrinsic motivation. In addition, feeling of lack of motivation is defined as amotivation. When people are unable to perceive the correlation between their actions and the results of these actions, amotivation occurs. These people are motivated neither intrinsically nor extrinsically. Those who are amotivated experience feelings of inadequacy, which leads to disappointment that they cannot control (Vallerand et al., 1992).

Self-efficacy perception, like motivation, is regarded as one of the most important factors that affect sporting achievements. Self-efficacy is defined as people's beliefs regarding their capability to succeed and attain a given level of performance (Bandura, 1977). Self-efficacy perception affects the emotions and opinions that enable individuals to strive, encourage them not to give up, overcome temporary obstacles, and control the events that affect their lives so that they can achieve their objectives (Gençtürk and Memiş, 2010). Bandura (1986) stresses that selfefficacy perception determines one's choice of activities, perseverance to overcome difficulties, the level of efforts, and performance, and these have been the focus of many studies. The findings from the relevant literature confirm Bandura's (1986) observations and reveal that in case of a difficult situation, an individual with high self- 
efficacy perception exerts more effort in order to achieve an objective, does not give up easily when facing obstacles and is persistent (Kiremit and Gökler, 2010).

Bandura (1986) assesses the factors that affect self-efficacy in four different dimensions: personal experiences; vicarious experiences of others; verbal persuasion, and physiological arousal. Personal experiences can be positive or negative, as experienced by the individuals themselves. Vicarious experiences are the experiences of individuals' social models and emerge as a result of positive or negative experiences of those people taken as models. Verbal persuasions are positive or negative feedback and evaluation by those around the individual. The final factor is physiological and emotional arousal, which explains that physiological and emotional status affects selfefficacy when the individual starts to act. For example, a positive mood increases self-efficacy whereas a negative mood affects it negatively (Figen and Mete, 2009). When the relevant studies are investigated, coaches emerge as a social factor that may affect athletes' self-efficacy perception. For example, it was revealed that there was a correlation between feedback and self-efficacy (Bandura and Cervone, 1983; van Dinther et al., 2011). Morever, recent research has shown that verbal and nonverbal behaviours of coaches may also influence athletes' self-efficacy (Saville and Bray, 2016). In this sense, it may be argued that coaching behaviours may affect athletes' selfefficacy.

When leadership is assessed, ignoring the characteristics of organisation, society and social as wel as political life will not allow to obtain accurate results. Members of the group that the leader guides are also a part of society and represent its characteristics. Therefore, it is essential to analyse in a detailed way the social and cultural characteristics of the society and of the group to which an individual belongs to present effective leadership behaviours (ErtanKantos, 2011).

There are very few studies that have examined Turkish coaches' perceived leadership behaviours (Eskiyecek et al., 2015; Ödemiş and Karagün, 2016; Türksoy and Şarkıcı, 2003). Furthermore, only one study on self-efficacy and coaching leadership behaviour exists including a
Turkish sample and this study was undertaken with taekwondo athletes (Cengiz et al., 2012). Moreover, to the best of authors' knowledge, there is no research in which the relationship between perceived coaching behaviour and athletes' sport motivation has been examined with participation of a Turkish sample. Regarding international literature, there is only one research on the relationship between coaching behaviours and athletes' self-efficacy (Saville and Bray, 2016) in which five dimensions of perceived coaching behaviour were not measured. Although there are some studies that have investigated the relationship between coaching behaviours and motivation (Abedini et al., 2014; Barić and Bucik, 2009; Wu et al., 2014; Zardoshtian et al., 2011), they do not reflect the characteristics of a Turkish sample as these studies dealt with athletes living within a different social structure specific for these countries and they differ in many aspects. Even living in the same country, athletes may demonstrate different psychological characteristics as they perform in different sporting areas and each sporting branch has distinct structures. Also, the relevant literature showed that the leadership behaviours of coaches preferred by different athletes may differ (Horn et al., 2011; Kaya and Canbaz, 2005; Riemer and Toon, 2001; Türksoy and Şarkıc1, 2003). In light of the aforementioned arguments, determining coaching leadership behaviours that affect the motivation and self-efficacy of wrestlers with different characteristics is important to have an insight into this issue which may help enhance self-beliefs and motivation of athletes. Therefore, the current study aimed to determine the relationship between perceived coaching behaviour, motivation and self-efficacy in wrestlers who competed in the Super National Wrestling League.

\section{Material and Methods}

\section{Population and Sample}

The population of the study consisted of wrestlers competing in the Greco-Roman style and Freestyle Super National Wrestling League (Level 1 of the national leagues) during the 201213 season. According to the information obtained from the interviews with the Turkish Wrestling Federation, there were a total of 44 sports clubs in the Super National Wrestling League; 22 sports 
clubs in freestyle wrestling and 22 sports clubs in the Greco-Roman style; 400 wrestlers were active in these clubs. The study sample was composed of 289 wrestlers from these sports clubs, recruited using the convenience sampling method. The participation in the study was voluntary. The average age of the athletes was $22.69 \pm 4.51$ years and the length of sport experience was $11.10 \pm 4.54$ years. Fifty-six athletes (19.4\%) were married and $233(80.6 \%)$ were single. One hundred and seventy nine wrestlers $(61.9 \%)$ competed in freestyle, while 110 athletes $(38.1 \%)$ wrestled in the Greco-Roman style.

\section{Data Collection Tools}

The data collection tools used in the study were composed of five parts. The first part included questions about the demographic characteristics of the participants. The second part consisted of a Self-Efficacy Scale to measure selfefficacy perception for sports. The third part comprised a Sports Motivation Scale, the fourth part included a Leadership Scale for Sport Athlete's Perception of Coach's Behaviour version - and the final part was based on General SelfEfficacy Scale.

Self-Efficacy Scale

The Self-Efficacy Scale was developed by Riggs et al. (1994) to measure individual's beliefs in their own capabilities. It contains 10 items and the participants decide how much they agree with the items on the scale by using a five point rating scale; numeric values marked for the item are added to get a single self-efficacy score. Some of the items are reverse-scored. The lowest score is 10 while the highest score is 50 . A high score indicates a strong self-efficacy belief. A sample item is "As an athlete I am confident with my abilities." The internal consistency coefficient calculated by Riggs et al. (1994) was 0.86. The Turkish adaptation of this scale was performed by Öcel and Aydin (2009). All of the items on the Self-Efficacy Scale are the athletes' own perceptions about their sporting skills, that is different from a general self-efficacy perception. The internal consistency coefficient calculated for the current study was 0.61 .

Sports Motivation Scale

The Sports Motivation Scale was developed by Pelletier et al. (1995) and consists of 28 items. The Turkish adaptation of the scale was performed by Kazak (2004). The items in the scale are answered based on the question: "Why do you do sports?". According to the answers, the levels of intrinsic motivation (sample item: For the pleasure it gives me to know more about the sport that I practice), extrinsic motivation (sample item: Because it allows me to be well regarded by people that I know) and amotivation (sample item: It is not clear to me anymore; I don't really think my place is in sport) are measured, and the reason for the motivation is determined. The internal consistency coefficients calculated for these subscales were $0.87,0.86$, and 0.60 , respectively. Leadership Scale for Sport

The Leadership Scale for Sport aims to measure five different leadership behaviours in relation to athletes' perception. Each behaviour was represented by one subscale. The scale was developed by Chelladurai and Saleh (1980) and is a five point Likert scale (always, often, occasionally, seldom, never) with 40 items. All items are preceded with the phrase "My coach $(\ldots)^{\prime \prime}$. The subscales focus on training and instruction behaviour (13 items; sample item: My coach explains to each athlete the techniques and tactics of the sport), democratic behaviour ( 9 items; sample item: My coach lets his/her athletes participate in decision making), autocratic behaviour (5 items; sample item: My coach speaks in a manner not to be questioned), social support behaviour (8 items; sample item: My coach encourages the athlete to confide in him/her) and positive feedback or reward behaviour (5 items; sample item: My coach expresses appreciation when his/her athlete performs well). The internal consistency coefficients calculated for these subscales were $0.90,0.86,0.59,0.83$, and 0.74 , respectively. The Turkish adaptation of the scale was made by Toros and Tiryaki (2006).

General Self-Efficacy Scale

This scale was originally developed by Sherer et al. (1982) and its Turkish adaptation was performed by Yıldırım and İlhan (2010). The scale measures individuals' general sense of perceived self-efficacy and it is a five point Likert scale, ranging from strongly disagree (1) to strongly agree (5), with 17 items. A sample item is "When I make plans, I am certain I can make them work". The lowest score that can be obtained from the scale is 17 and the highest score is 85 . High scores indicate an increased general self-efficacy 
perception. The internal consistency coefficient calculated for the current study was 0.87 .

\section{Data Collection}

Ethical approval for the present study was obtained from the Kocaeli University Clinical Research Ethical Committee with the project number of KOU KAEK 2012/50. The athletes were contacted in their clubs. Verbal consent from the sports clubs' management staff and sports coaches was obtained. The athletes were informed that participation was voluntary and the data they would provide would be used only for the purpose of the research. All the questionnaires were filled in by the participants in face to face interactions on their sports clubs' premises.

\section{Data Analysis}

In general, a test should present reliability of 0.7 and higher to be considered useful (Nunnally, 1978), however, it was also stated that an acceptable level of internal consistency could be 0.60 in social sciences (Aron and Aron, 1999). The Cronbach's alpha value for the autocratic behaviour subscale in this research was 0.59. Although this value was low, it was very close to the threshold. Therefore, we decided to keep this subscale unchanged and to include it in further analysis. It should be noted that the results related to this subscale should be treated with caution.

For data analyses, descriptive statistics and linear regression analyses (enter method) were used. The level of significance was set at 05 . An adequate sample size is necessary for regression analysis and, according to Tabachnick and Fidell (2007), the formula $\mathrm{N}>50+8 \mathrm{~m}(\mathrm{~m}=$ number of independent variables) can be used to calculate a sufficient sample size. The Tabachnik and Fidell's (2007) formula confirmed that the sample size of the present research was sufficient. Outliers in the variables were also detected to ensure the suitability of the data for further analysis. Any observation between the z score of 3.3 and 3.3 was suggested to be an outlier (Pallant, 2007). Z scores for every observation in each variable showed that the values were between the stated scores. After confirming the normal distribution of the data, parametric analysis was performed. Also, the correlation coefficients indicated that multicollinearity was not present.

\section{Results}

Descriptive statistics about wrestlers' perceived coaching behaviours, motivation and self-efficacy perception as well as the Cronbach's alpha values for the subdimensions are presented in Table 1.

Multiple regression analyses were performed in order to determine to what extent the athletes' perception of coaching behaviours explained athletes' self-efficacy scores. Table 2 shows that the most important perceived coaching behaviour that explained the selfefficacy score was social support behaviour $(\beta=$ .31). The second greatest contribution to the model was from training and instruction behaviour $(\beta=.30)$. Social support behaviour as well as training and instruction behaviour explained $3 \%$ of the variance in the self-efficacy scores (adjusted $\mathrm{R}^{2}=.03, \mathrm{~F}=2.88, p<.05$ ). Democratic behaviour, autocratic behaviour and positive feedback behaviour (rewarding behaviour) did not make a significant contribution to the regression model $(p>.05)$.

Multiple regression analyses were conducted in order to determine to what extent athletes' perception of coaching behaviours explained their general self-efficacy scores. Table 3 shows that training and instruction behaviour, along with social support behaviour and autocratic behaviour scores contributed to the model. The most effective variable that explained general self-efficacy scores was training and instruction behaviour $(\beta=.51)$. The second biggest contribution was made by social support behaviour $(\beta=-.27)$ and the third by autocratic behaviour $(\beta=-.17)$. Training and instruction behaviour, social support behaviour and autocratic behaviour scores explained $10 \%$ of the total variance in the general self-efficacy scores (adjusted $\mathrm{R}^{2}=.10, \mathrm{~F}=7.45, p<.05$ ). Democratic behaviour and positive feedback behaviour (rewarding behaviour) scores did not make a significant contribution to the regression model $(p$ $>$.05).

Multiple regression analyses were conducted in order to explore to what extent athletes' perception of coaching behaviours explained their intrinsic motivation. Table 4 shows that the scores of training and instruction behaviour and social support behaviour contributed considerably to intrinsic motivation. The most effective variable that explained intrinsic motivation was training and instruction 
behaviour $(\beta=.40)$ and the second greatest contribution was made by social support behaviour $(\beta=-.32)$.

The scores of training and instruction behaviour and social support behaviour explained $4 \%$ of total variance in intrinsic motivation (adjusted $\mathrm{R}^{2}=.04, \mathrm{~F}=3.54, p<.05$ ). Democratic behaviour, autocratic behaviour and positive feedback behaviour (rewarding behaviour) did not significantly explain the intrinsic motivation $(p>.05)$.

In order to explore to what extent the wrestlers' perception of coaching behaviours explained their amotivation, multiple regression analyses were conducted. Table 5 shows that the scores of training and instruction behaviour as well as social support behaviour contributed to the model. The most effective variable that influenced the level of amotivation was training and instruction behaviour $(\beta=.50)$ and the second greatest contribution was made by social support behaviour $(\beta=.32)$.

The scores of training and instruction behaviour along with social support behaviour explained $5 \%$ of total variance in amotivation (adjusted $\mathrm{R}^{2-}=.05, \mathrm{~F}=4.25, p<.05$ ). Democratic behaviour, autocratic behaviour and positive feedback behaviour (rewarding behaviour) did not make a significant contribution to the model $(p>.05)$.

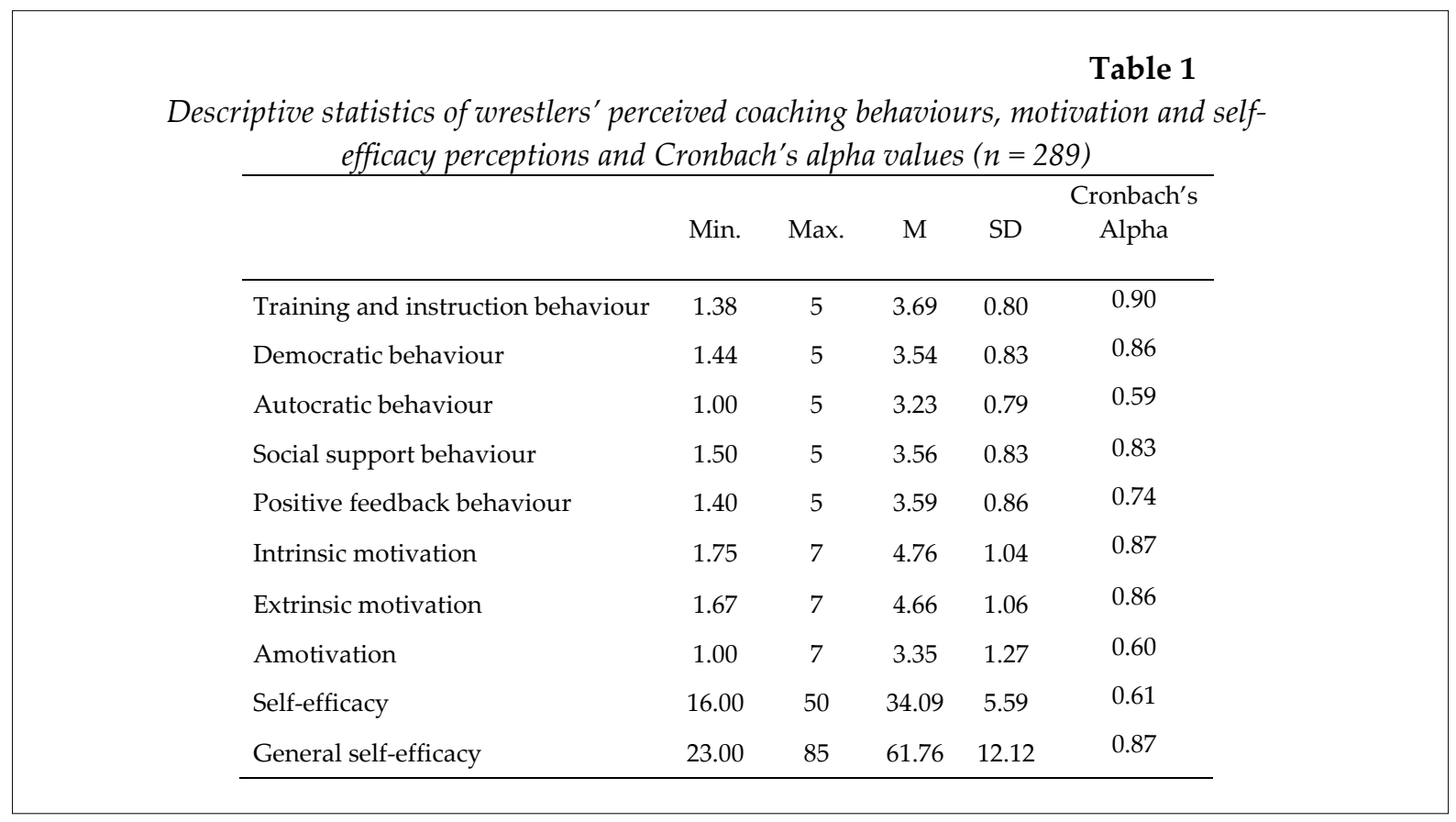

\begin{tabular}{|c|c|c|c|c|c|c|}
\hline \multicolumn{7}{|c|}{$\begin{array}{r}\text { Results of multiple-regression analyses concerning per } \\
\text { athletes' self-efficacy }\end{array}$} \\
\hline \multirow{2}{*}{ Independent variables } & \multicolumn{2}{|c|}{$\begin{array}{l}\text { Unstandardized } \\
\text { Coefficients }\end{array}$} & \multicolumn{2}{|c|}{$\begin{array}{l}\text { Standardized } \\
\text { Coefficients }\end{array}$} & \multirow{2}{*}{$\mathrm{t}$} & \multirow{2}{*}{$p$} \\
\hline & B & SE & $\beta$ & SE & & \\
\hline $\begin{array}{l}\text { Training and instruction } \\
\text { behaviour }\end{array}$ & 2.13 & .86 & .30 & .12 & 2.48 & $.01^{*}$ \\
\hline Democratic behaviour & 1.38 & .88 & .21 & .13 & 1.57 & .12 \\
\hline Autocratic behaviour & -.78 & .47 & -.11 & .07 & -1.67 & .10 \\
\hline Social support behaviour & -2.11 & .80 & -.31 & .12 & -2.65 & $.01^{*}$ \\
\hline Positive feedback behaviour & -.85 & .64 & -.13 & .10 & -1.34 & .18 \\
\hline \multicolumn{7}{|c|}{$\begin{array}{l}R^{2}=.05, \text { Adjusted } R^{2}=.03, F=2.88, p<.05 \\
* p<.05, \text { dependent variable }=\text { Self-efficacy. }\end{array}$} \\
\hline
\end{tabular}


Table 3

Results of multiple-regression analyses concerning perceived coaching behaviours and general self-efficacy

\begin{tabular}{lccccccc}
\hline \multirow{2}{*}{\multicolumn{1}{c}{ Independent variables }} & \multicolumn{2}{c}{$\begin{array}{c}\text { Unstandardiz } \\
\text { ed }\end{array}$} & $\begin{array}{c}\text { Standardized } \\
\text { Coefficients }\end{array}$ & & & $p$ \\
\cline { 2 - 6 } & Coefficients & SE & $\beta$ & SE & & \\
\hline Training and instruction behaviour & 7.73 & 1.79 & .51 & .12 & 4.31 & $.00^{*}$ \\
Democratic behaviour & .02 & 1.84 & .00 & .13 & .01 & .99 \\
Autocratic behaviour & -2.57 & .98 & -.17 & .06 & -2.62 & $.01^{*}$ \\
Social support behaviour & -4.00 & 1.67 & -.27 & .11 & -2.40 & $.02^{*}$ \\
Positive feedback behaviour & 1.03 & 1.34 & .07 & .10 & .77 & .44 \\
\hline
\end{tabular}

$R^{2}=.12$, Adjusted $R^{2}=.10, F=7.43, p<.05$

$* p<.05$, dependent variable $=$ General self-efficacy

Table 4

Results of multiple-regression analyses concerning perceived coaching behaviours and intrinsic motivation

\begin{tabular}{|c|c|c|c|c|c|c|}
\hline \multirow{2}{*}{ Independent variables } & \multicolumn{2}{|c|}{$\begin{array}{l}\text { Unstandardized } \\
\text { Coefficients }\end{array}$} & \multicolumn{2}{|c|}{$\begin{array}{l}\text { Standardized } \\
\text { Coefficients }\end{array}$} & \multirow{2}{*}{$\mathrm{t}$} & \multirow{2}{*}{$p$} \\
\hline & B & SE & $\beta$ & SE & & \\
\hline $\begin{array}{l}\text { Training and instruction } \\
\text { behaviour }\end{array}$ & .53 & .16 & .40 & .12 & 3.31 & $.00^{*}$ \\
\hline Democratic behaviour & .04 & .16 & .03 & .13 & .27 & .79 \\
\hline Autocratic behaviour & -.17 & .09 & -.13 & .07 & -1.97 & .05 \\
\hline Social support behaviour & -.41 & .15 & -.32 & .12 & -2.75 & $.01^{*}$ \\
\hline Positive feedback behaviour & .01 & .12 & .00 & .10 & .04 & .97 \\
\hline
\end{tabular}

$R^{2}=.06$ Adjusted $R^{2}=.04, F=3.54, p<.05$

${ }^{*} p<.05$, dependent variable $=$ Intrinsic motivation

Table 5

Results of multiple-regression analyses concerning perceived coaching behaviours and amotivation

\begin{tabular}{|c|c|c|c|c|c|c|}
\hline \multirow[t]{2}{*}{ Independent variables } & \multicolumn{2}{|c|}{$\begin{array}{c}\text { Unstandardized } \\
\text { Coefficients }\end{array}$} & \multicolumn{2}{|c|}{$\begin{array}{c}\text { Standardized } \\
\text { Coefficients }\end{array}$} & \multirow[t]{2}{*}{$t$} & \multirow{2}{*}{$p$} \\
\hline & B & SE & $\beta$ & & & \\
\hline Training and instruction behaviour & -.80 & .19 & -.50 & .12 & -4.14 & $.00^{*}$ \\
\hline Democratic behaviour & .02 & .20 & .01 & .13 & .09 & .93 \\
\hline Autocratic behaviour & .18 & .11 & .11 & .07 & 1.67 & .10 \\
\hline Social support behaviour & .49 & .18 & .32 & .12 & 2.75 & $.01^{*}$ \\
\hline Positive feedback behaviour & .09 & .14 & .06 & .10 & .62 & .54 \\
\hline
\end{tabular}




\section{Discussion}

The findings of this research show that while the wrestlers' perception of sports coaches' training and instruction behaviour may be beneficial for athletes' intrinsic motivation and amotivation, perceived social support behaviour may be detrimental for these two motivation types. When the relationship between the athletes' perception of coaching behaviours and athletes' motivation is examined, personal and cultural differences, the needs of individuals as well as the fact that these needs may change from person to person should be taken into consideration. In this regard, findings from the present study demonstrate the characteristics and features of athletes who wrestled in the freestyle and GrecoRoman style in the Super National Wrestling League.

As explained, it was noted that coaches' perceived social support behaviour appeared to be detrimental for intrinsic motivation of the athletes. The study carried out by Demir and Okan (2009) concurred with this finding and revealed that contrary to theoretical expectations, there was a negative relationship between collectivism in national culture and social needs. Their findings were not as expected because collectivism in national culture contains the features of social relationships. People living in collectivistic cultures aim at harmonious relationships with the community to which they belong. It has been stated that Turkish society presents a collectivistic structure (Sargut, 2001). In this regard, the negative relationship between perceived social support behaviour and intrinsic motivation was not expected. Similarly, it was expected that the social support behaviour perception of athletes living in a collectivist country, such as Turkey (Hofstede, 2001), would be positively related to intrinsic motivation, however, the opposite findings were obtained. The conclusions of Amorose and Horn (2001) may explain this phenomenon. After some time, coaching behaviours, such as showing social support behaviour, developing a strong relationship with athletes, and caring for and supporting the athletes may cause the athletes to make an effort and practice in order not to disappoint their coaches; a situation in which athletes may feel under pressure. Thus, motivation may occur to meet the coaches' expectations rather than due to intrinsic reasons. This may explain why there is not a positive correlation between perceived social support behaviour and intrinsic motivation in the current study (Amorose and Horn, 2001). Moreover, the specific characteristics of the study group (sport experience, gender, attitudes of their family towards sports, etc.) may have also affected this relationship. For example, the athletes' average sport experience in the current study was $11.10 \pm$ 4.54 years, which shows the expertise of the sample group. Furthermore, considering that these athletes competed in the super league, it may be said that they were elite athletes and leadership behaviours affecting the intrinsic motivation of such a group may differ from coaching behaviours regarded important for a much less experienced group of athletes who have just started practicing a particular sports discipline.

There are studies on motivation and coaching behaviours that have been undertaken with different sample groups. For instance, some emphasise that athletes' motivation is positively affected by coaching behaviours that encourage athletes to show autonomous behaviours (Amorose and Anderson-Butcher, 2007; Banack et al., 2011; Vallerand, 2007). Moreover, in a study carried out by Barić and Bucik (2009), it was reported that coaches should demonstrate training and instruction behaviour, social support behaviour, and positive feedback behaviour (rewarding behaviour) in order to increase athletes' intrinsic motivation. The study of Mouratidis et al. (2010), conducted in Greece, points out that athletes' motivation is positively affected if the coaches communicate supporting athletes' autonomy perceptions instead of autocratic behaviour. In the study of Nazarudin et al. (2009), conducted with Malaysian athletes, it was noted that athletes most preferred coaches to show training and instruction behaviours. Also, in another research it was found that perceived training and instruction behaviour along with democratic behaviour of coaches made a positive contribution to intrinsic motivation of Iranian volleyball players, whereas perceived autocratic behaviour negatively influenced intrinsic motivation (Zardoshtian et al., 2011). Similarly, Amorose and Horn (2001) stated that increases in the athletes' level of intrinsic motivation were 
associated with athletes' perceptions that their coaches exhibited high frequencies of training and instruction behavior and low freuencies of autocratic and social support behaviour.

According to the regression analyses that examined the relationship between athletes' selfefficacy and perceived coaching behaviours, we observed that perceived training and instruction behaviour along with social support behaviour explained the self-efficacy by $3 \%$, which was very low, altough significant. Examining which perceived coaching behaviour explained the athletes' general self-efficacy, it was found that training and instruction behaviour, along with autocratic behaviour and social support behaviour explained the general self-efficacy scores by $10 \%$. $\quad \beta$ coefficients showed that perceived training and instruction behaviour was beneficial for athletes' self-efficacy and general self efficacy. However, perceived autocratic behaviour and social support behaviour appeared to be harmful for general self-efficacy. Similarly, social support behaviour was also harmful for the self-efficacy perception of athletes. It may be concluded that, as the athletes perceive that coaches exhibit more training and instruction behaviour, their self-efficacy and general selfefficacy levels increase. It is possible that when a coach shows training and instruction behaviour and tries to eliminate athletes' faults, athletes perceive and understand that the coach has some expectations of the athletes which may positively affect the athletes' self-efficacy perception. Previous studies concurred with this conclusion. For example, the study of Rosenthal and Jacobson (1968) indicated that the expectations of people had effects upon others. Therefore, the positive relationship between perceived training and instruction behaviour, wrestlers' self-efficacy and general self-efficacy was in line with the expectations in this research.

To the authors' knowledge, not many studies have examined the relationship between coaching behaviours and athletes' self-efficacy perception. In Turkey, there has been only one study that investigated this relationship, and the five dimensions of coaching behaviours that taekwondo athletes perceived were found to be positively correlated with athletes' self-efficacy (Cengiz et al., 2012). Since there is a limited number of studies in different countries, those studies investigating this topic in another relevant field may direct the discussions. For example, it can be argued that the fact that sales people are autonomous and can make decisions on their own is associated with their self-efficacy. Including individuals in the decision-making process and enabling them to become more autonomous in their jobs mean that their decisions and choices are trusted by their superiors. Since managers trust in sales people's skills and competences, they allow them to act on their own while they carry out their responsibilities, which strengthens sales people's self-efficacy perception. In an autonomous setting where sales people decide on their own, they try to fulfil their responsibilities by using their skills, knowledge and creativity. The methods used make them aware of their knowledge, abilities and skills and thus, affect their self-efficacy perception (Wang and Netemeyer, 2002). In this regard, if coaches demonstrate autocratic behaviours and do not include the athletes in the decision-making process, athletes may think that their decisions are not trusted. Likewise, those who cannot show skills, develop strategies, employ techniques and tactics, use their creativity and knowledge, may not discover their skills. These reasons may explain the negative relationship between perceived autocratic coaching behaviours and wrestlers' general self-efficacy. Besides this, it was also reported that elite coaches used methods such as a positive self-talk, instructional activities and providing positive feedback to increase athletes' self-efficacy (Gould et al., 1989). The results obtained in this research should be interpreted cautiously as there are some limitations to be noted. Firstly, since the study sample was drawn from Turkish wrestlers, it is not representative of Turkish athletes as a whole. Secondly, the study sample was selected by a convenience sampling method, thus it may not be fully representative. Lastly, self-report measures were used as the data collection tools. Thus, more objective measures may strengthen future research.

\section{Conclusions and Implications}

The current study aimed to determine the relationship between perceived coaching behaviours, motivation, self-efficacy and general self-efficacy of wrestlers who competed in the 
Super National Wrestling League. It may be suggested that perceived training and instruction behaviour of coaches was beneficial for wrestlers' self-efficacy, general self-efficacy, intrinsic motivation, and amotivation scores. Analysing the findings concerning perceived autocratic coaching behaviours, it was identified that autocratic behaviours may be detrimental for wrestlers' general self-efficacy. As for perceived social support behaviour in the regression model, it negatively explained self-efficacy, general selfefficacy, intrinsic motivation, and amotivation, which implies that perceived social support behaviour may be detrimental for these variables.

The findings of this research showed that perceived training and instruction behaviour, which prioritizes training and instructing the athletes to develop their skills, was positively related to athletes' motivation, self-efficacy and general self-efficacy. Therefore, based on the results, it may be suggested that wrestling coaches should exhibit training and instructing behaviour. Also, the results indicated that perceived autocratic coaching behaviour was negatively related to athletes' general self-efficacy. Therefore, it could be suggested that autocratic coaching behaviour should be avoided by the coaches and more democratic behaviours could be employed by letting athletes participate in the decision making process. Lastly, the results indicated that perceived social support behaviour may not always be positive for wrestlers' selfefficacy, general self-efficacy and motivation, thus sport coaches should cautiously exhibit social support behaviour. Further research focused on coaching behaviours that may affect motivation and self-efficacy of athletes' with different characteristics (culture, age, sportive experience, gender, sportive branches, education, etc.) is necessary.

\section{Acknowledgements}

This paper is based on the doctoral dissertation written by the first author and submitted to the Kocaeli University. We thank Professor Dr F. Hülya Aş̧̧ı for her comments on an earlier draft of this paper. Her recommendations added invaluable contributions.

\section{References}

Abedini M, Esmaili M, Tojari F. The relationship between coaching leadership styles and achievement motivation of iran's professional and amateurish fencers. International Journal of Sport Studies, 2014; 4(7): 744-750

Adie J W, Duda JL, Ntoumanis N. Autonomy support, basic need satisfaction and the optimal functioning of adult male and female sport participants: A test of basic needs theory. Motiv Emot, 2008; 32(3): 189-199

Altıntaş A, Kelecek S, Aşçı FH. Relationships between situational motivation and flow experience in elite athletes. Pamukkale Journal of Sport Sciences, 2013; 4(4): 14-21

Amorose AJ, Anderson-Butcher D. Autonomy-supportive coaching and self-determined motivation in high school and college athletes: A test of self-determination theory. Psychol Sport Exerc, 2007; 8(5): 654-670

Amorose AJ, Horn TS. Pre-to post-season changes in the intrinsic motivation of first year college athletes: Relationships with coaching behavior and scholarship status. J Appl Sport Psychol, 2001; 13(4): 355-373

Aron A, Aron EN. Statistics for psychology. Prentice Hall/Pearson Education; 1999

Banack HR, Sabiston CM, Bloom GA. Coach autonomy support, basic need satisfaction, and intrinsic motivation of paralympic athletes. Res Q Exerc Sport, 2011; 82(4): 722-730

Bandura A. Self-efficacy: Toward a unifying theory of behavioral change. Psychol Rev, 1977; 84(2): 191-215

Bandura A. Social foundation of thought and action: A social cognitive theory. Englewood Cliffs, NJ: Prentice Hall; 1986

Bandura A, Cervone D. Self-evaluative and self-efficacy mechanisms governing the motivational effects of goal systems. J Pers Soc Psychol, 1983; 45(5): 1017-1028

Barcza-Renner K, Eklund RC, Morin AJ, Habeeb CM. Controlling coaching behaviors and athlete burnout: 
Investigating the mediating roles of perfectionism and motivation. J Sport Exerc Psychol, 2016; 38(1):3044

Barić R, Bucik V. Motivational differences in athletes trained by coaches of different motivational and leadership profiles. Kinesiology, 2009; 41(2): 181-194

Bum CH, Shin SH. The Relationships between Coaches' Leadership Styles, Competitive State Anxiety, and Golf Performance in Korean Junior Golfers. Sport Science Review, 2015; 24(5-6): 371-386

Cengiz R, Aytan GK, Abakay U. The relationship between self-efficacy levels and leadership qualities that the taekwondo athlete perceive. e-Journal of New World Sciences Academy, 2012; 7(4): 68-78

Chelladurai P, Saleh SD. Dimensions of leader behavior in sports: development a leadership scale. J Sport Psychol, 1980; 2: 34-45

Chelladurai P. Leadership in sport. A review. Int J Sport Psychol, 1990; 21(4): 328-354

Chelladurai P. Leadership. In R. N. Singer, M. Murphy, \& L. K. Tennant (Eds.), Handbook on Research on Sport Psychology (pp. 647-671). New York: McMillan; 1993

Cheval B, Chalabaev A, Quested E, Courvoisier DS, Sarrazin, P. How perceived autonomy support and controlling coach behaviors are related to well-and ill-being in elite soccer players: A within-person changes and between-person differences analysis. Psychol Sport Exerc, 2017; 28: 68-77

Clancy RB, Herring MP, MacIntyre TE, Campbell MJ. A review of competitive sport motivation research. Psychol Sport Exerc, 2016; 27: 232-242

Deci EL, Ryan RM. Intrinsic Motivation and Self-determination in Human Behavior, Plenum Press, New York; 1985

Demir H, Okan T. The effect of national culture on motivation. Gazi Üniversitesi İktisadi ve İdari Bilimler Fakültesi Dergisi, 2009; 11(1): 121-142

Doğan O. Sport Pychology. Sivas: Cumhuriyet University Press; 2004

Ertan-Kantos Z. Leadership in Organization Metaphors: A Conceptual Analysis. Journal of Educational Sciences Research, 2011; 1(1): 135-158

Eskiyecek CG, Bayazıt B, Sarı İ. The investigation in terms of age gender and sports of coach leadership behaviours preferred in athletes (the sample of Diyarbakır). International Refereed Academic Journal of Sports, Health and Medical Sciences, 2015; 5(15): 27-42

Figen PS, Mete S. Use of Adaptation Model and Social Cognitive Theory in Prenatal Education. Dokuz Eylül Üniversitesi Hemşirelik Yüksekokulu Elektronik Dergisi, 2009; 1(1): 57-68

Gençtürk A, Memiş A. An Investigation of Primary School Teachers' Teacher Efficacy and Job Satisfaction in Terms of Demographic Factors. Elementary Education Online, 2010; 9(3): 1037-1054

Gould D, Hodge K, Peterson K, Giannini J. An exploratory examination of strategies used by elite coaches to enhance self-efficacy in athletes. J Sport Exerc Psychol, 1989; 11(2): 128-140

Hofstede G. Culture's Consequences (2nd ed.): Comparing values, behaviors, institutions and organizations across nations. Thousand Oaks, CA: Sage; 2001

Hollembeak J, Amorose AJ. Perceived coaching behaviors and college athletes' intrinsic motivation: A test of self-determination theory. J Appl Sport Psychol, 2005; 17(1): 20-36

Horn TS, Bloom S, Berglund KM, Packard S. Relationship between collegiate athletes' psychological characteristics and their preferences for different types of coaching behavior. Sport Psychol, 2011; 25(2): 190-211

Jõesaar H, Hein V, Hagger MS. Youth athletes' perception of autonomy support from the coach, peer motivational climate and intrinsic motivation in sport setting: One-year effects. Psychol Sport Exerc, 2012; 13(3): 257-262

Kaufmann N, Schulze T, Veit D. More than fun and money. worker motivation in crowdsourcing-a study on mechanical Turk. Proceedings of the Seventeenth Americas Conference on Information Systems, Detroit, Michigan August 4th-7th, 1-11; 2011

Kaya Y, Canbaz M. Examining motivational factors of taekwondo athletes on perception dimension in terms 
of their relationship with their coaches. Selçuk University, the Journal of Institute of Social Science, 2005; 14: 377-392

Kazak Z. A study on reliability and validity of "the sport motivation scale -sms-" for Turkish athletes. Hacettepe Journal of Sport Sciences, 2004; 15(4): 191-206

Kiremit HÖ, Gökler İ. Comparison of Preservice Science Teachers' Self-Efficacy Beliefs in Teaching Biology. Pamukkale University Journal of Education, 2010; 27: 41-54

Körük E, Biçer T, Donuk B. Determination of the Amateur Soccer Coaches Lidership Styles and The Motivation Techniques They Use. Istanbul University Journal of Sport Sciences, 2003; 11(3): 53-57

Ledochowski L, Unterrainer C, Ruedl G, Schnitzer M, Kopp M. Quality of life, coach behaviour and competitive anxiety in Winter Youth Olympic Games participants. Brit J Sport Med, 2012; 46(15): 10441047

Matosic D, Cox AE, Amorose AJ. Scholarship status, controlling coaching behavior, and intrinsic motivation in collegiate swimmers: A test of cognitive evaluation theory. Sport, Exercise, and Performance Psychology, 2014; 3(1): 1-12

Morsünbül Ü. Autonomy and Its Effect on Mental Health. Current Approaches in Psychiatry, 2012; 4(2): 260278

Mouratidis A, Lens W, Vansteenkiste M. How you provide corrective feedback makes a difference: the motivating role of communicating in an autonomy-supporting way. J Sport Exerc Psychol, 2010; 32(5): 619-637

Nazarudin BHNM, Fauzee OSM, Jamalis M, Geok KS, Din A. Coaching leadership styles and Athlete Satisfaction Among Malaysian University Basketball Team. Research Journal of International Studies, 2009; 9(1): 4-11

Nicolas M, Gaudreau P, Franche V. Perception of coaching behaviors, coping, and achievement in a sport competition. J Sport Exerc Psychol, 2011; 33(3): 460-468

Nicholls AR, Morley D, Perry JL. Mentally tough athletes are more aware of unsupportive coaching behaviours: Perceptions of coach behaviour, motivational climate, and mental toughness in sport. Int J Sports Sci Coach, 2016; 11(2): 172-181

Nunnally JC. Psychometric Theory. Second Edition. McGraw-Hill Book Company; 1978

Öcel H, Aydın O. The relationships of collective efficacy beliefs, self efficacy beliefs and group cohesiveness with success evaluations and expectancies in sports teams. Journal of Faculty of Letters, 2009; 26(2): 155174

Ödemiş M, Karagün E. Leadership behaviours that dance athletes perceive and prefer. Journal of Human Sciences, 2016; 13(3): 5201-5213

Pallant J. SPSS survival manual: A step-by-step guide to data analysis using SPSS version 15. Nova Iorque: McGraw Hill; 2007

Pelletier LG, Fortier MS, Vallerand RJ, Tuson KM, Briere NM, Blais MR. Toward a new measure of intrinsic motivation, extrinsic motivation, and amotivation in sports: The Sport Motivation Scale (SMS). J Sport Exerc Psychol, 1995; 17: 35-35

Reinboth M, Duda JL, Ntoumanis N. Dimensions of coaching behavior, need satisfaction, and the psychological and physical welfare of young athletes. Motiv Emot, 2004; 28(3): 297-313

Riemer HA, Toon K. Leadership and satisfaction in tennis: Examination of congruence, gender, and ability. Res Q Exercise Sport, 2001; 72(3): 243-256

Riggs ML, Warka J, Babasa B, Betancourt R, Hooker S. Development and validation of self-efficacy and outcome expectancy scales for job-related applications. Educ Psychol Meas, 1994; 54: 793-802

Roberts GC, Treasure DC. Advances in Motivation in Sport and Exercise, 3E: Human Kinetics; 2001

Rosenthal R, Jacobson L. Pygmalion in the classroom. Urban Rev, 1968; 3(1): 16-20

Sargut SA. Cross-cultural differentiation and management, İmge Publishing, Ankara; 2001

Saville PD, Bray SR. Athletes' perceptions of coaching behavior, relation-inferred self-efficacy (rise), and self- 
efficacy in youth sport. J Appl Sport Psychol, 2016; 28(1): 1-13

Sherer M, Maddux JE, Mercandante B, Prentice-Dunn S, Jacobs B, Rogers RW. The self-efficacy scale: Construction and validation. Psychol Rep, 1982; 51(2): 663-671

Stebbings J, Taylor IM, Spray CM. Antecedents of Perceived Coach Autonomy Supportive and Controlling Behaviors: Coach Psychological Need Satisfaction and Well-Being, J Sport Exerc Psychol, 2011; 33(2): $255-272$

Tabachnick BG, Fidell LS. Using Multivariate Statistics (5th edition). Boston: Pearson Education; 2007

Toros T. Analysis the differentiation between perceived coaching behaviors, goal orientation, team cohesion, perceived motivational climate ve collective efficacy among the young male basketball players before and after the tournament. Pamukkale Journal of Sport Sciences, 2011; 2(1): 27-39

Toros T, Duvan A. The relationship between perceived coaching behaviours, collective efficacy and goal orientation among fencer players in Turkey. Nigde University Journal of Physical Education and Sport Sciences, 2011; 5(1): 33-41

Toros T, Tiryaki Ş. Validity and reliability studuy of Leadership Scale for Sports -football players' perception of sports coaching behaviours version. Proceeding of the $9^{\text {th }}$ International Sport Science Congress, pp.1320-1322. 3-5 November, Muğla, Turkey; 2006

Türksoy A, Şarkıcı T. 12-14 age range football players satisfaction on the perceived and preferred with the leader behaviors of their coaches. Istanbul University Journal of Sport Sciences, 2003; 11(3): 200-203

Vallerand RJ. Intrinsic and extrinsic motivation in sport and physical activity. A review an a look at the future. In G. Tenenbaum, \& R. C. Eklund (Eds.), Handbook of sport psychology (3rd ed., pp. 59-83). New York: Wiley; 2007

Vallerand RJ, Pelletier LG, Blais MR, Briere NM, Senecal C, Valleres EF. The academic motivation scale: a measure of intrinsic, extrinsic and amotivation in education. Educ Psychol Meas, 1992; 52(4): 1003-1017

Van Dinther M, Dochy F, Segers M. Factors affecting students' self-efficacy in higher education. Educational Research Review, 2011; 6(2): 95-108

Vealey RS, Armstrong L, Comar W, Greenleaf CA. Influence of perceived coaching behaviors on burnout and competitive anxiety in female college athletes. J Appl Sports Psychol, 1998; 10(2): 297-318

Wang G, Netemeyer RG. The effects of job autonomy, customer demandingness, and trait competitiveness on salesperson learning, self-efficacy, and performance. J Acad Mark Sci, 2002; 30(3): 217-228

Weaver J, Moses JF, Snyder M. Self-Fulfilling Prophecies in Ability Settings. J Soc Psychol, 2016; 156(2): 179189

Wu AMS, Lai MHC, Chan IT. Coaching behaviors, satisfaction of needs, and intrinsic motivation among Chinese university athletes. J Appl Sport Psychol, 2014; 26(3): 334-348

Yıldırım F, İlhan İ. Validity and Reliability Study of the Turkish Form of the General Self-efficacy Scale. Turkish Journal of Psychiatry, 2010; 21(4): 301-308

Zardoshtian S, Naghshbandi S, Jabari N. Predicting self-determined motivation of elite female volleyball players from leadership styles of coaches in Iran. International Journal of Sports Science and Engineering, 2011; 5(4): 219-224

\section{Corresponding author:}

\section{İhsan Sarı}

Address: Sakarya Üniversitesi Spor Bilimleri Fakültesi, 54187 Serdivan/Sakarya, Turkey.

Phone: 902642957341

Fax: 902642956642

Email: sariihsan@yahoo.com 